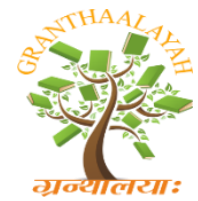

$$
\begin{aligned}
& \text { INTERNATIONAL JOURNAL OF RE } \\
& \text { GRANTHAALAYAH } \\
& \text { A knowledge Repository }
\end{aligned}
$$

Science

\title{
COMPARISON OF CARDIOVASCULAR ENDURANCE AND SPEED BETWEEN URBAN AND RURAL FEMALE STUDENTS OF BAHAUDDIN ZAKARIYA UNIVERSITY PAKISTAN
}

\author{
Syed Muhammad Ghufran Hadier Hamdani ${ }^{* 1}$, Dr QingZhong He ${ }^{2}$, Syeda Urooj Fatima \\ Hamdani ${ }^{3}$, Syed Muhammad Zeeshan Haider Hamdani ${ }^{4}$, Syed Muhammad Danish \\ Haider Hamdani 5 \\ ${ }^{* 1,2}$ Faculty of Athletics, Beijing Sports University, Beijing, China \\ ${ }^{3}$ Department of Sports Sciences, Government College University Faisalabad, Pakistan \\ ${ }^{4}$ Department of Sports kinesiology, Shanghai University of Sport, Shanghai, China \\ ${ }^{5}$ Department of Sports Sciences, Beijing Sports University, Beijing, China
}

DOI: https://doi.org/10.29121/granthaalayah.v5.i5.2017.1868

\begin{abstract}
The purpose of the present study was to determine which group of female students urban/rural has better physical fitness performance in tests. Samples comprised of 72 females' students (36 urban and 36 rural), this represented $10 \%$ of the population from each school of Bahauddin Zakariya University Multan Pakistan. Two physical Fitness components: speed and cardiovascular endurance were assessed using 60 Meters Speed test for speed and Harward Step Test for cardiovascular endurance. Descriptive Statistics examine the characteristics of the samples and Independent ' $t$ ' test was employed using IBM SPSS Statistics 22 software. The results indicated that urban girls' performance was superior to the rural girls in speed (9.29Mean) and cardiovascular endurance (5.97Mean) in both physical fitness tests urban girls' physical fitness level was higher. The findings of this study proved that the results of this study are unique and shows that urban girls have more physical fitness trend than urban girls, moreover it was also discovered for future studies that the cultural, social and living environment had a great impact on the physical fitness of females in Pakistan.
\end{abstract}

Keywords: Endurance; Speed; Physical Fitness; Urban; Rural.

Cite This Article: Syed Muhammad Ghufran Hadier Hamdani, Dr QingZhong He, Syeda Urooj Fatima Hamdani, Syed Muhammad Zeeshan Haider Hamdani, and Syed Muhammad Danish Haider Hamdani. (2017). "COMPARISON OF CARDIOVASCULAR ENDURANCE AND SPEED BETWEEN URBAN AND RURAL FEMALE STUDENTS OF BAHAUDDIN ZAKARIYA UNIVERSITY PAKISTAN." International Journal of Research Granthaalayah, 5(5), 361-366. https://doi.org/10.29121/granthaalayah.v5.i5.2017.1868. 


\section{Introduction}

The perplexing human body and its systems in a sound condition are the real gift for us by nature. At present a healthy life is prodigious endowment of God in the real sense. With the progression of time and distinctive developments in the industrial and the scientific revolution upheaval the entire situation, human life has been changed entirely. Before those discoveries and innovations that have made human life easier people rely upon their own energy and individual strength for the satisfaction of requirements.

This is the reason; they are ace master in some essential capacities and expertise named as agility in all action, endurance, physical strength, speed, and specialist skills like jumping, climbing and numerous other diverse capacities used in pursuing their livings said by (Manmeet 2010) [1]. But modernization and advancement in technology have changed our lifestyle and it has also affected our physical fitness badly because of less activity.

Ability and capacity to perform daily routine activities and task enthusiastically and effectively are named as Physical fitness of a person. Physical fitness incorporates segments of games as well as those of well-being too. Our daily physical activity helps us in the prevention of weight gaining, helps to pick up in body mass index (BMI) said by (Kyle 2001) [2].

Very low ratio of physical activity of a person and cardio-respiratory wellness both are related to higher danger in all cause and sickness particular mortality said by (Thune et al. 1998) [3]. A person who possesses a good physical fitness can perform effective running, climbing, jumping, and weight lifting. He can proceed with consistent, moderate or vigorous physical activities, exercises or sports more productively as well as he can be more successful in recreational activities and everyday life. There is a big difference between the urban and rural people's lives as the environment of both places is totally different. Similarly, the quality and quantity of their food consumption, their lifestyle, the culture of the society, health standards, economic issues etc. are the common factors affecting the physical fitness and development of the girls.

Urbanization has additionally impacted the physical capability of individuals for instance; urban girls have less domestic work to do, because they have modern facilities and better technology, contrary girls from the rural region don't have maids like urban people, so they are frequently busy in doing their domestic work, as well as field work along with the school education. Rural girls are more involved in physical exertion from their childhood On the other hand, urban girls are not, they have the proper equipment, training, liberal environment to perform physical activities or sports, due to feasible environment, freedom of society, parental support helps them to build and boost their confidence level which is an important aspect of any sports or physical performance. Good nutrition has always supported the good sport or physical performance that is the reason, because rural girls have fresh, healthy food quality and more domestic physical exertion, so these are the reasons girls from the rural area seem to be healthier, physically fitter and good at sports. But lack of confidence, ignorance about physical education is the downside of their personality.

(Choudhary 1998) found a distinct difference in his study physical fitness of urban and rural students of 9th, 10th class and finds out that the physical fitness dimension of rural area students 
is better over the urban area students [4]. (Uppal and Sareen 2000) Had investigated the cardiovascular fitness of both urban and rural area students and found out that the students belong to the rural area performed the physical activities better than their counterparts in the urban area [5].

Like above mentioned and many other similar studies those had been carried out on same phenomena, one may conclude that the girls belong to the urban area are not better in physical fitness than the rural girls. But here one thing is essentially important; every society, every individual is not the same as one another. Because of various circumstances such as social values, cultural traits, environment and facilities. So, if American, Australian, European, ruralurban girls both are physically fit, we can't assume that it's equivalent in Asia, Africa or Pakistan. There are couples of conditions those change the situation, for example, changes in Body structure, their physical fitness level, weather, available facilities since American or Australian rural girls have better knowledge, facilities, coaching and liberal culture however girls in Pakistan don't have the same conditions.

In the case of Pakistan, most of the rural girls are used to do their domestic work, they even can't imagine the facilities those are available to urban girls. Even in most of the rural schools, there is no physical education instructor available. In urban schools, Girls have two or three physical education instructors and this can be considered the reason for the rural girl to be unaware of the significance of physical fitness. Better nourishment and a lot of physical work in daily routine purportedly appear in the better physical health of rural young girls. But urban girls have distinctive favorable circumstances, for example, accessibility of better gear, great training from the specialists in the urban area, those aren't accessible in the rural area. However, there are few aspects that the girls from the urban area have excessive access to the good nourishment and economic status of their parents. Urban girls are increasingly empowered and spurred by their instructors and mentors.

The Greece children from urban areas had significantly better performance level in vertical jump and basketball throw compared to rural children[6], McNaughton et al. reported that the Tasmanian boys and girls had greater aerobic fitness than the rural children[7]. Adult girls from the urban regions are usually bigger in body size and have more fast rhythm of maturation than kids of rural area of the encompassing and surrounding countryside area. It additionally has been said that youngsters from the urban area are tall in height and heavy in weight than their rustic partners, has been founded by (Tanner 1989) [8]. Several studies evaluated physical fitness profiles of people in different categories, including urban and female university students in the India, the United States and the European countries. However, relatively no research had been done in Pakistan and very little information is accessible about physical fitness of girls in South Punjab. This circumstance required an investigation to determine the level of Physical Fitness of urban and rural female students in Bahauddin Zakariya University Multan.

\section{Methodology}

Subject: Subject selection for this study is carried out by using systematic random sampling. Researcher had selected 72 students from different Schools of Bahauddin Zakariya University Multan; enrolled in session of 2015-2016 as subjects for this present study, Among them 32 
belonged to rural areas of south Punjab and rest from urban area of south Punjab from various teaching departments of Bahauddin Zakariya University Multan, department were Sports Science, English, History, Physics, Pharmacy, Computer Science, BBA, Psychology, and Mathematics. The urban females' average age mean is 21.39 , minimum age is 17 and the maximum age is 26. Rural females' average age mean is 21.17 , minimum age is 18 and the maximum age is 26 . The urban females' average weight mean is 54.56 , minimum weight is 34 and the maximum weight is 77 . Rural females' average weight mean is 54.92, minimum weight is 38 and the maximum weight is 90 .

Variables Selection: In table 1 the insights about the variable had been given for the present review and those had been measured.

Statistical Technique: Descriptive statistics and Independent' $t$ ' test was employed to each variable for comparing the mean values of physical fitness variables between rural and urban children. The significance levels were set at 0.05 . SPSS 22 was used to execute the statistical functions.

\section{Results}

After the conversion of raw data into a group, the different statistical test had been used to find out the necessary information. The findings and the results are given and illustrated through the tables below.

Table 1: Selected variables details of test

\begin{tabular}{|l|l|l|}
\hline S. No. & Variables & Tests \\
\hline 1 & Cardiovascular Endurance & Harward Step Test \\
\hline 2 & Speed & 60 Meters Speed test \\
\hline
\end{tabular}

Table 1 shows the variables and their criterion measures that had been used in this study.

Table 2: Mean and standard deviation of urban and rural female students for both tests

\begin{tabular}{|c|c|c|c|c|}
\hline Test & Group Urban/Rural & $\overline{\mathbf{N}}$ & Mean & Std. Deviation \\
\hline Cardiovascular Endurance by & Urban & 36 & 5.97 & 1.183 \\
\hline Harvard Step Test & Rural & 36 & 5.75 & .967 \\
\hline $\begin{array}{l}\text { Speed(sec) by } 60 \text { Meters Speed } \\
\text { test }\end{array}$ & $\begin{array}{l}\text { Urban } \\
\text { Rural }\end{array}$ & $\begin{array}{l}36 \\
36\end{array}$ & $\begin{array}{l}9.29 \\
9.52\end{array}$ & $\begin{array}{l}1.745 \\
1.846\end{array}$ \\
\hline
\end{tabular}

Table 2 shows the combined results of Harvard Step Test and 60 Meters Speed test.

Table 3: Comparative analysis Report of 60 Meters Speed (sec) test between urban and rural female student

\begin{tabular}{|l|l|l|l|}
\hline Group/Urban or Rural & N & Mean & Std. Deviation \\
\hline Urban & 36 & 9.29 & 1.745 \\
Rural & 36 & 9.52 & 1.846 \\
Total & 72 & 9.40 & 1.787 \\
\hline
\end{tabular}

Table 3 shows the mean, Std. Deviation of 60 Meters Speed test The mean and Std. Deviation of 60 Meters Speed test of urban and rural girls were recorded as group wise urban girls Mean 9.29(sec), Std. Deviation 1.745 and rural Mean 9.52(sec), Std. Deviation 1.846. Results show that urban students have performed better than rural girls in the tests. 
Table 4: Comparative analysis Report of Harvard Step Test between urban and rural female student

\begin{tabular}{|l|l|l|l|}
\hline Group/Urban or Rural & $\mathbf{N}$ & Mean & Std. Deviation \\
\hline Urban & 36 & 5.97 & 1.183 \\
Rural & 36 & 5.75 & .967 \\
Total & 72 & 5.86 & 1.079 \\
\hline
\end{tabular}

Table 4 shows the mean and Std. Deviation of Harvard Step Test

The mean and Std. Deviation, of Harvard Step Test of urban and rural girls were recorded as group wise, urban girls Mean 5.97(according to coding comes under the Excellent standard criteria), Std. Deviation 1.183 and rural girls Mean 5.75, Std. Deviation 0.967, Std. Error of Mean 0.161. Results show that the urban girls performed better than their rural counterparts in the tests.

Table 5: t-test of urban and rural female student (Significant at 0.05)

\begin{tabular}{|l|l|l|l|}
\hline \multirow{2}{*}{ Variables } & Rural $(\mathbf{N}=\mathbf{3 6})$ & Urban $(\mathbf{N}=\mathbf{3 6})$ & \multirow{2}{*}{ t-Value } \\
\cline { 2 - 3 } & Mean & Mean & .523 \\
\hline Speed (in sec) by 60 Meters Speed test & 9.52 & 9.29 & .769 \\
\hline Cardiovascular Endurance By Harvard Step Test & 5.75 & 5.97 & \\
\hline
\end{tabular}

The perusal of table 5 reveals that there lies a significant statistical difference between endurance of urban and rural females Athletes in Bahauddin Zakariya University, results revealed that the Urban students were found to have significantly better performance in Cardiovascular Endurance (t-value=.769) and also Urban students have better performance in speed ( $\mathrm{t}$-value $=.523$ ) compared to rural students in Bahauddin Zakariya University.

\section{Discussion}

The purpose of this study was to compare the level of physical fitness among students living in either urban or rural settings. The results of present study showed that the urban female students had performed significantly better in almost all the physical fitness variables of this study as compared to rural female students. The literature advocates that the person's living environment had a huge influenced on person physical fitness and conditions. Few studies had carried out in different countries such as US, Brazilian, Croatian, Mexican and Ecuadorian urban children have better physical fitness than rural areas students $[8,9,10]$. At same time some studies from Poland and Turkey showed that rural children were better physical fit than their urban children [11, 12]. Corlett JT. (1988, 1987) examined the physical wellness of Hungarys 3 to18 years' old children and discovers that the urban conditions had beneficially affected the physical wellness of the urban areas children and their execution was better in fitness tests [13, 14, 15]. McNaughton et al. reported that the Tasmanian boys and girls had greater aerobic fitness than the rural children [16]. The given research results differentiate between rural and urban females, because of the facilities available in urban areas are not being provided in rural areas such as better health facilities, liberal environment, parents supports, better coaches, religion boundaries and impatience among the Muslim society and misconceptions about females those involved in sports and physical activity. But these haven't yet provided in rural area of Pakistan. There is still a marked difference in rural and urban areas in Punjab. In the urban area females have many facilities like proper training, knowledge about health risk, parents support to do physical activity and girls are confident comparatively to rural girls. 


\section{Conclusion}

The present study concluded that urban female students are comparatively better than rural female students in Bahauddin Zakariya University; it clearly shows that the living environment had too much impact on the physical fitness of urban female students of the university. Urban female students are superior to rural female students in Cardiovascular Endurance and Speed. The contrast between the lifestyle, guardian's supports, activity levels, nutrition tendencies may have assumed a remarkable job in the contrasts between physical wellness of rural and urban female students of university.

\section{References}

[1] Manmeet Gill, Nishan Singh Deol and Ramanjit Kaur. (2010). Comparative Study of Physical Fitness Components of Rural and Urban Female Students of Punjabi University, Patiala:

[2] Anthropologist,12(1): 17-21

[3] Kyle U G, Gremion G, Genton L, Slosman DO, Golay A, Pichard C. (2001). Physical activity and fat free and fat mass as measured by bioelectrical impedence in 3853 adults. Med Sci Sports Exerc, 33: 576-584.

[4] Thune I, Njolstad I, Lochen ML, Forde OH 1998. Physical activity improves the metabolic risk profiles in men and women. Arch Intern Med, 158: 1633-1645.

[5] Choudhary Anchal 1998. Physical Fitness of Female Students Studying in High Schools in Rural and Urban Areas. M.Phil Thesis, Unpublished. Kurukshetra: Kuruskhetra University.

[6] Uppal AK, Sareen Rajeev (2000). Cardiovascular endurance of rural and urban school students. Research Bulletin, Research Division, L.N.I.P.E Gwalior, 15: 11-13.

[7] Tsimeas PD, Tsiokanos AL, Koutedakis Y, Tsigilis N, Kellis S. Does living in urban or rural settings affect aspects of physical fitness in children? An allometric approach. British

[8] Mc Naughton L, Morgan R, Smith P, Hannan G. An investigation into the fitness levels of Tasmanian primary schoolchildren. The ACHPER Healthy Lifestyles Journal 1996; 43(1):4-10.

[9] Tanner GM. Foetus into man, Physical Growth from Conception to Maturity, 2nd Ed. Castlemead Publication, 1989.

[10] Charles, M. (2006). Difference in health for rural and urban Canadians. Public Health News, Article Data 21 Sep. 2006-0:00 PST.

[11] Andrade S, Ochoa-Avilés A, Lachat C, Escobar P, Verstraeten R, John Van Camp JV et al. Physical fitness among urban and rural Ecuadorian adolescents and its association with blood lipids: a cross sectional study. BMC Pediatrics 2014; 14:106-116.

[12] Mazzuco M, Siqueira A, Giana S. Differences in anthropometrical and fitness variables among male students from Brazilian urban and rural schools. Medicine and Science in Sports and Exercise 2006; 38(5):S214- S215.

[13] McMurray RG, Harrell JS, Bangdiwala SI. Cardiovascular disease risk factors and obesity of rural and urban elementary school children. Journal of Rural Health 1999; 15:365-74.

[14] Das P, Chatterjee P. Urban-rural contrasts in motor fitness components of youngster footballers in West Bengal. India J Hum Sport Exerc 2013; 8(3):797-805.

[15] Ozdirenc M, Ozcan A, Akin F, Gelecek N. Physical fitness in rural children compared with urban children in Turkey. Pediatrics International 2005; 47(1):26-31.

[16] Corlett JT. Strength development of Tswana children. Human Biology 1988; 60:569-577.

[17] Corlett JT, Mokgwathi MM. Running performance of Tswana children. Physical Education Review 1987; 10:110-113.

*Corresponding author.

E-mail address: ghufranhamdani77@gmail.com 